\title{
Timothy Prus (2017). The cow and the orchid: generic colombian photography. Editorial La Silueta
}

\section{Santiago Rueda Fajardo}

Investigador independiente

$-$

Recibido: 10 de diciembre de 2017

Aprobado: 20 de diciembre de 2017

Cómo citar este artículo: Timothy Prus (2017). The cow and the orchid: generic colombian photography. Editorial la Silueta (reseña). Calle14: revista de investigación en el campo del arte, 13 (23) pp. 224-229 DOI: pendiente 

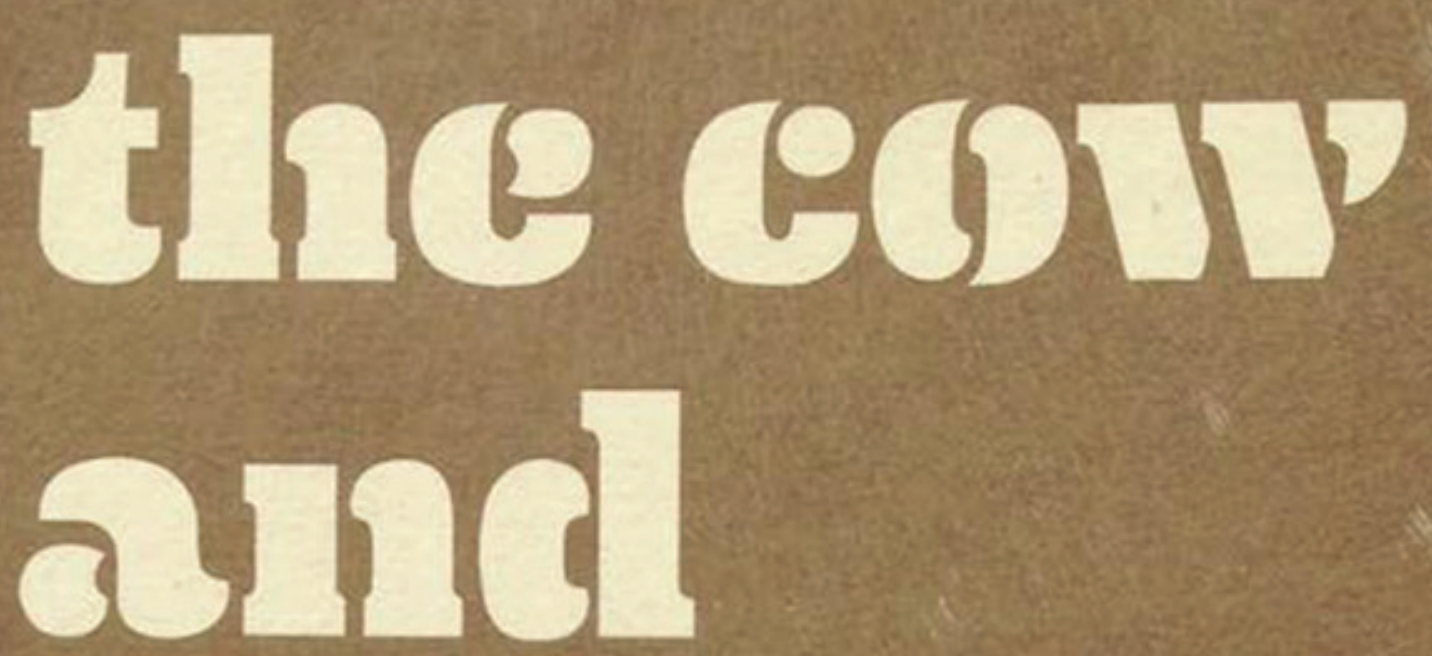

i

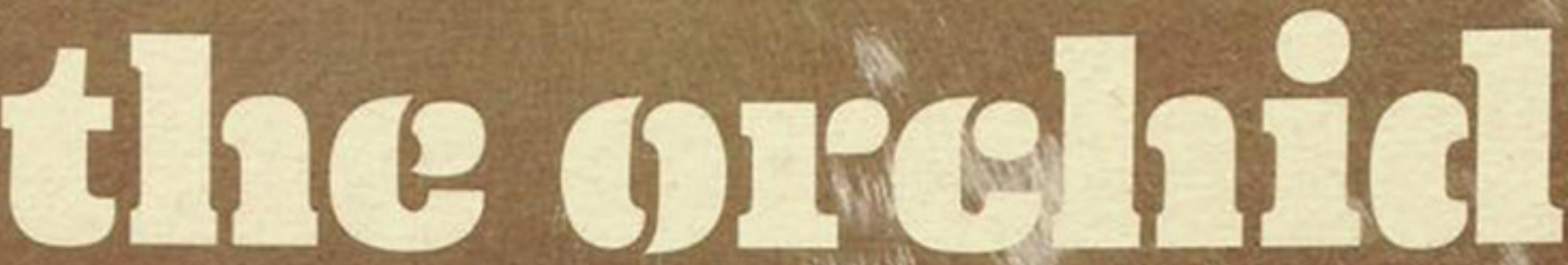

GENERIC COLOMBIAN PHOTOGRAPHY * ITH
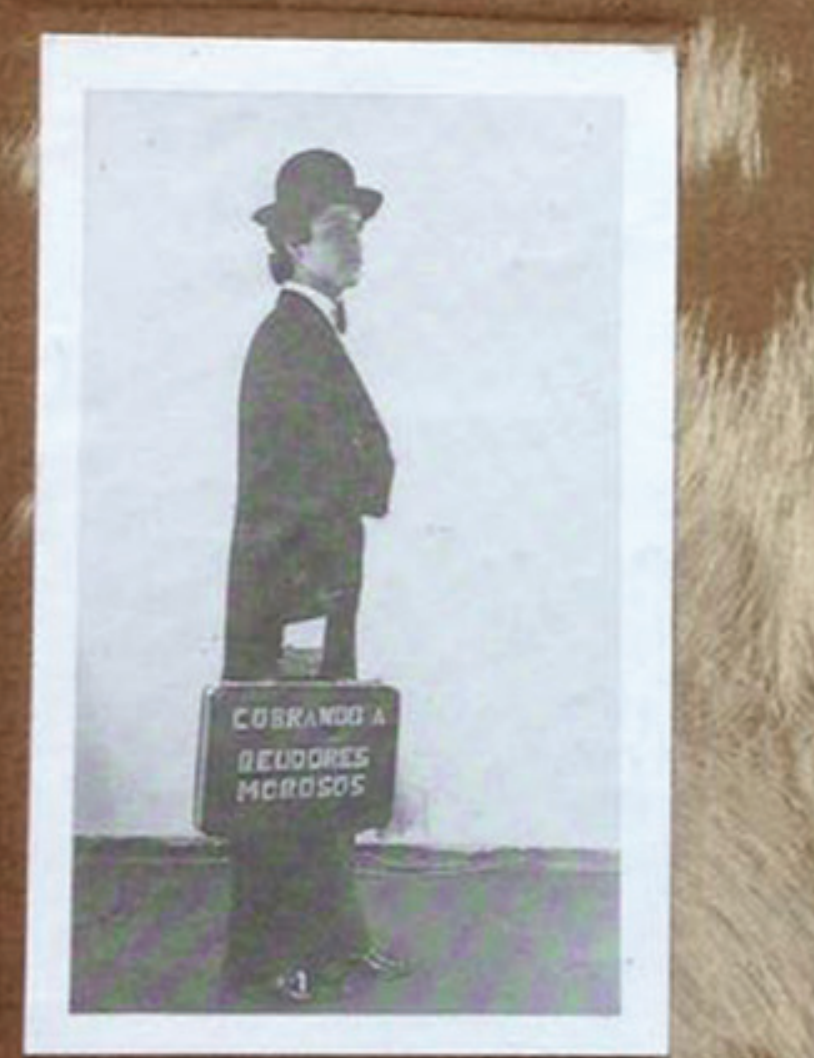
i. Whation

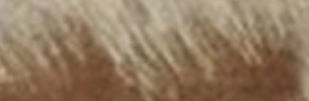

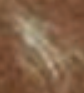

we
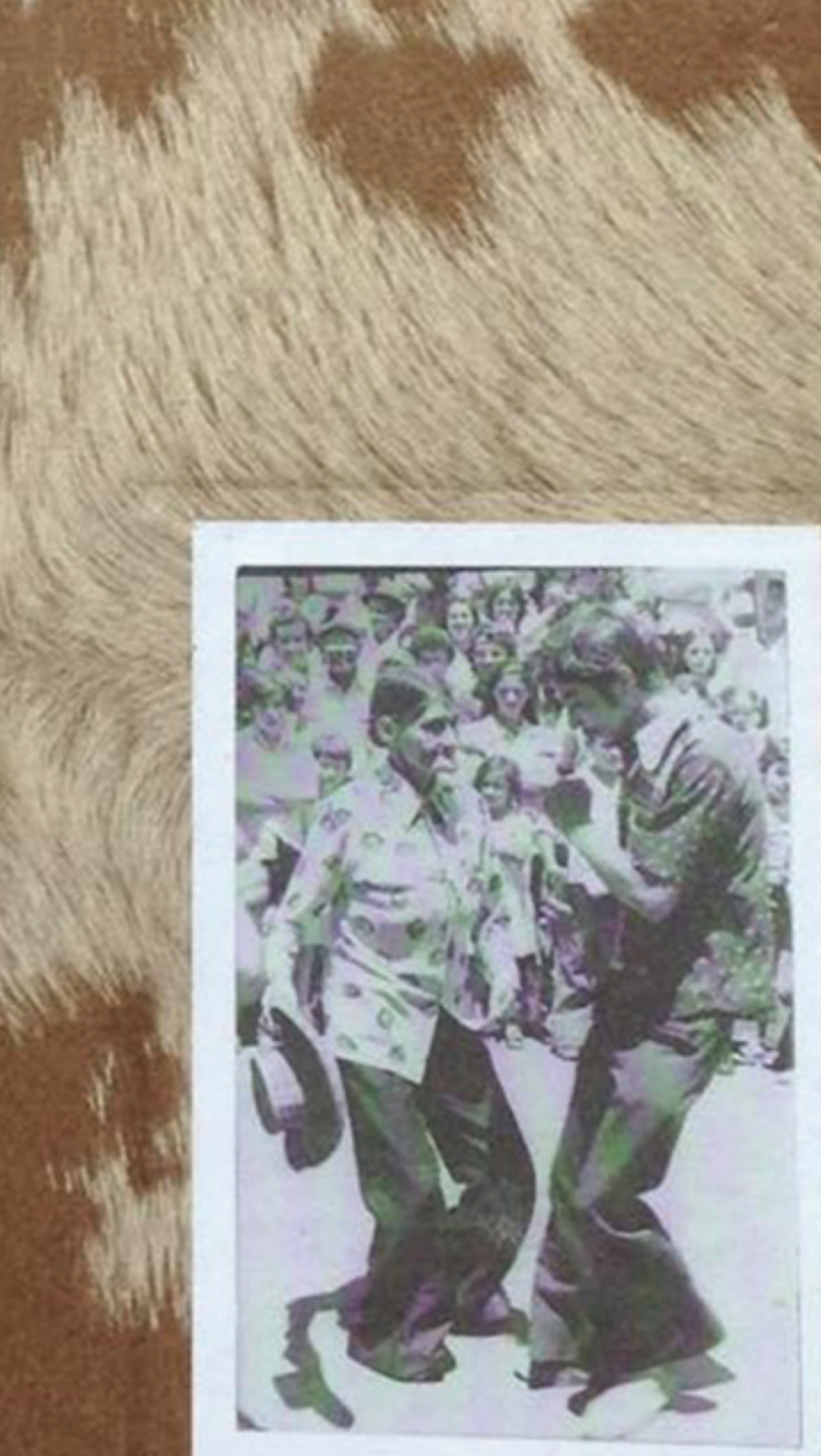
Pocos han sido los ingleses que se han interesado en la historia de Colombia, contados quienes se han interesado en su fotografía. Una de las pocas excepciones ha sido el historiador Malcom Deas, quien ha escrito y curado exposiciones donde ambas se unen. Su exposición Historia de Colombia a través de su fotografía 1842-2010 (2011), fue un sobrio y personal intento por parte de unos de los colombianistas más queridos en el país, por interpretar visualmente una esencia de esta nación. Es a la vez un ejemplo y un estímulo - deseablemente- para que los historiadores que trabajan sobre este país, se animen a realizar curadurías e investigaciones visuales y acerquen y se acerquen, por medio de ellas, al gran público.

Timothy Prus, fundador, curador y editor del Archive of the modern conflict, con sede en Londres, es otro de los pocos ciudadanos británicos que se han interesado en la historia, la fotografía y la historia de la fotografía colombiana. Aunque constantemente ha afirmado ser apenas un visitante ocasional a nuestro país, su libro
La vaca y la orquídea, fotografía genérica colombiana, recientemente editado por la editorial La Silueta, única en interesarse seriamente por la fotografía en este país, demuestra que Prus ha entendido y disfrutado el alma de los colombianos.

Partiendo de que es muy difícil construir un argumento, que permita entender lo que sucede en una nación compleja, diversa y literalmente explosiva, se vale de una estrategia inesperada pero que resultará, más aleccionadora de lo esperado. En la introducción al libro afirma:

Nadie duda que a la Reina Victoria le hubiese encantado Colombia. Se sabe que sufría un delirio por las orquídeas y que nombró Experto Real en Orquídeas a un oficial llamado Frederick Sanders. La reina también tenía aprecio por las vacas. Hermosos especímenes ennoblecieron las ganaderías reales y ganaron varios premios. Tristemente no hay nada sobre Victoria o Fred en esta exhibición, pero no debemos tener remordimientos. Las fotos

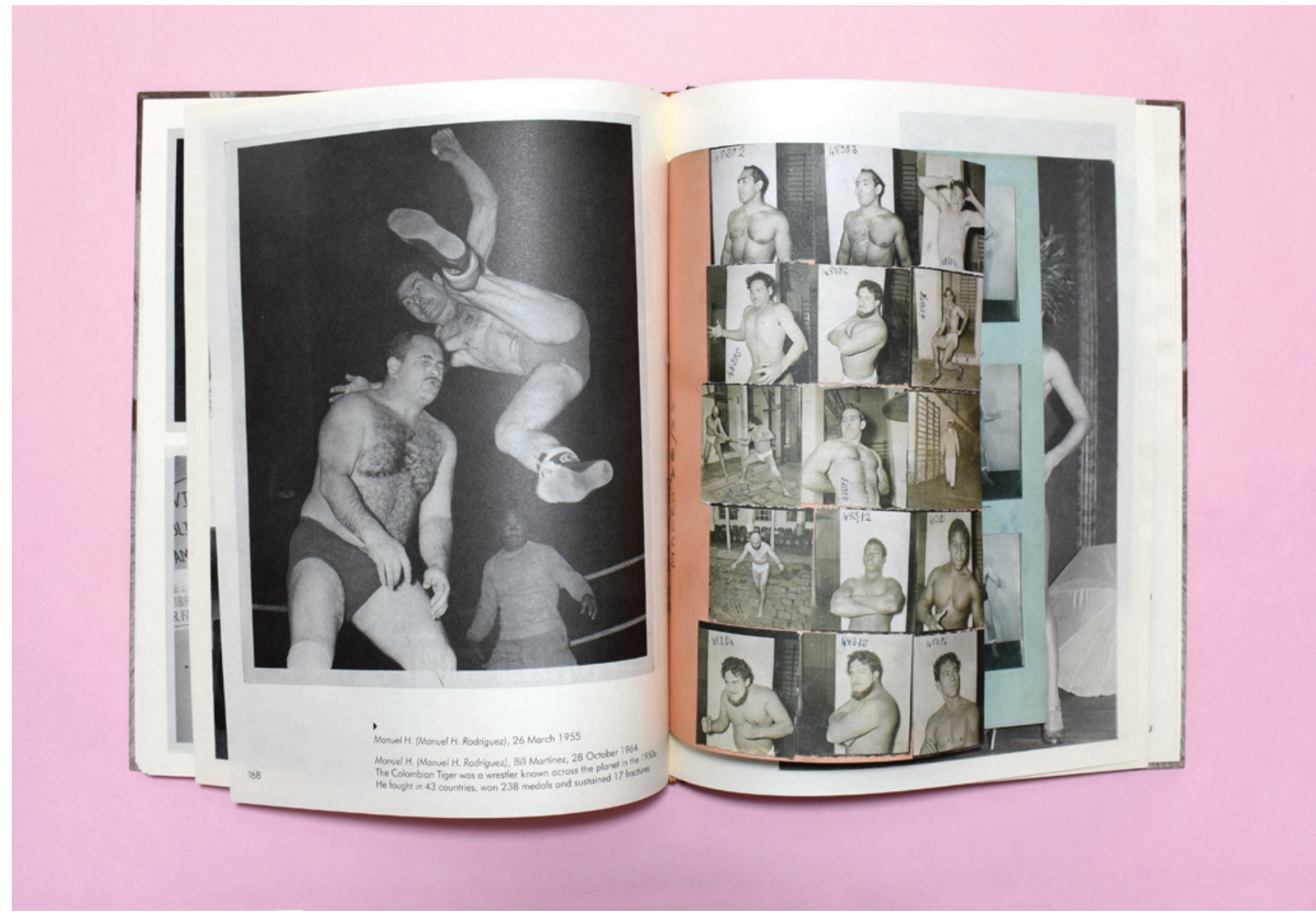

Imagen del libro: The cow and the orchid: generic colombian photography. Cortesía de Timothy Prus y La Silueta Ediciones (Valeria Giraldo, Andrés Fresneda y Juan Pablo Fajardo). 


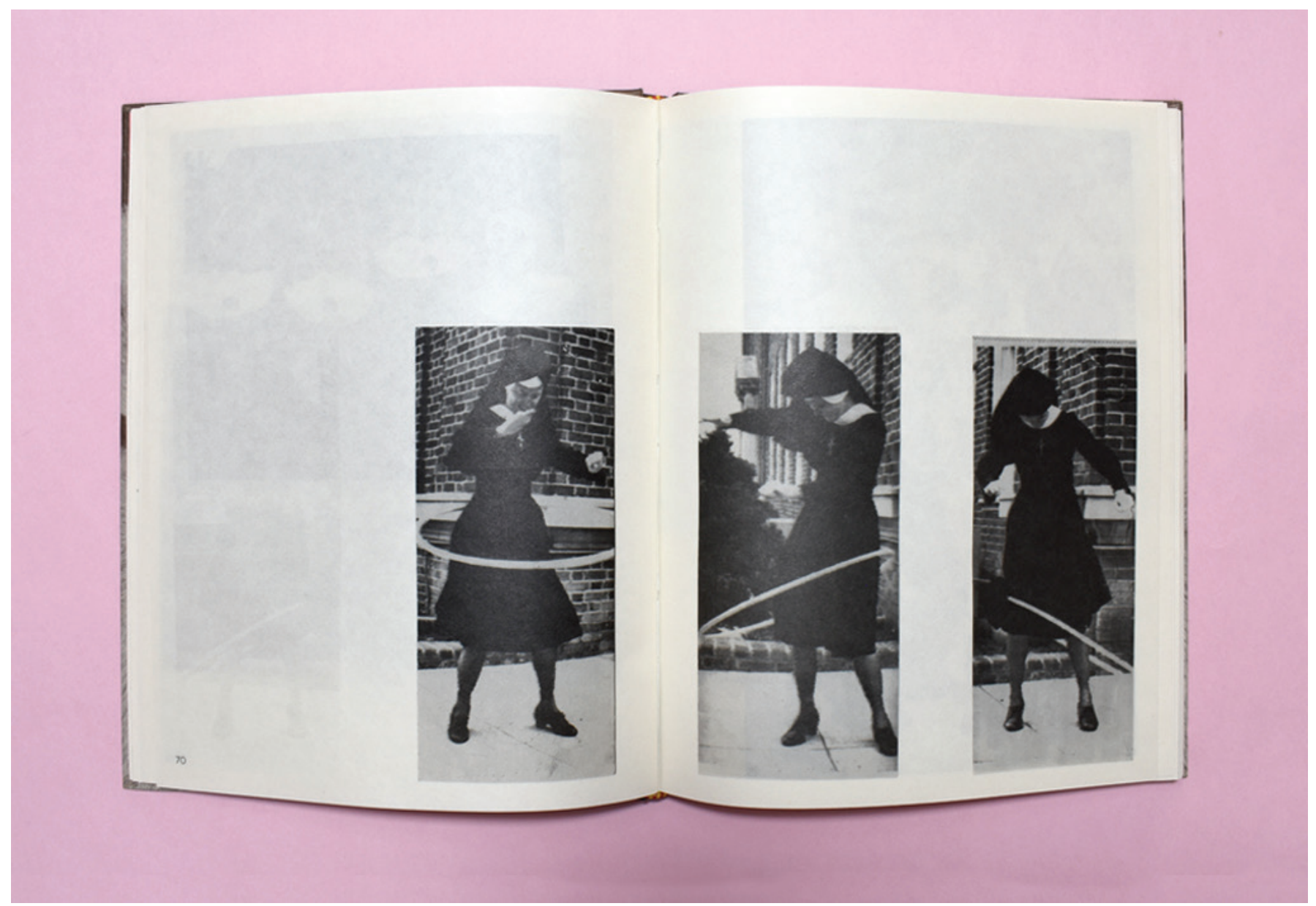

Imagen del libro: The cow and the orchid: generic colombian photography. Cortesía de Timothy Prus y La Silueta Ediciones (Valeria Giraldo, Andrés Fresneda y Juan Pablo Fajardo).

aquí reunidas fueron recolectadas durante un viaje de 12 años a través de Colombia. No se dejó piedra sin levantar en esta búsqueda por la verdadera fotografía genérica de este país. Y así como la colección crecía, una visión emergió que era la vez cercana a Europa, y al mismo tiempo infinitamente más misteriosa de lo que podríamos haber imaginado. ¿Nos ayudarán ellas a entender el territorio de una manera más profunda? Definitivamente no. Continúa siendo un enigma. Mezclar los siglos XIX, XX y XXI, fuerza al tiempo a doblarse sobre sí mismo. ¿Más claro? Bueno, quizá es una nimiedad.

La sensual orquídea es uno de los símbolos nacionales de Colombia. La vaca, plácida y generosa, es un símbolo de nada. El lugar entre las dos — como la fotografía- es ambiguo. Y así encontramos un país donde el hacer imágenes pulsa como una fiesta a la que todos estamos invitados."

En la vaca y la orquídea casi no hay detalle que escape a Prus de ésta vida genérica: Los niños colinchados en los camiones, la lluvia bogotana, la orinada en el muro, las carretas de tracción humana y las zorras, los perros callejeros, Kápax, "El comanche", la procesión de semana Santa, la primera comunión, la vuelta Colombia, la venta de cocinol, el radio transistor que se llevaba al estadio, los guachimanes, la tacada de billar, los reinados, los campeones de lucha libre, la rumba, el petaco de cerveza, la cantina de leche; y los lugares: El almacén " mi tiendita ", que posiblemente existe en todos los barrios populares y pueblos del país, la plaza de Bolívar en Bogotá, la inundación de Guatavita la vieja, las Salinas de Zipaquirá; y así como aparecen las fotografías también aparecen los géneros fotográficos: la tarjeta de visita, la foto callejera y de foto agüitas, el álbum familiar, imagen de prensa; y los fotógrafos : Félix Tisnes, Gabriel Carvajal, Ángel Vargas, Manuel H, Ángelo Vargas, Guadalupe Ruíz.

Prus descubre un acontecimiento olvidado, el rodaje de algunas escenas en la plaza de Bolívar de la película Los aventureros de 1968, protagonizada por Charles Aznavour y Candice Bergen, según Prus, una película 


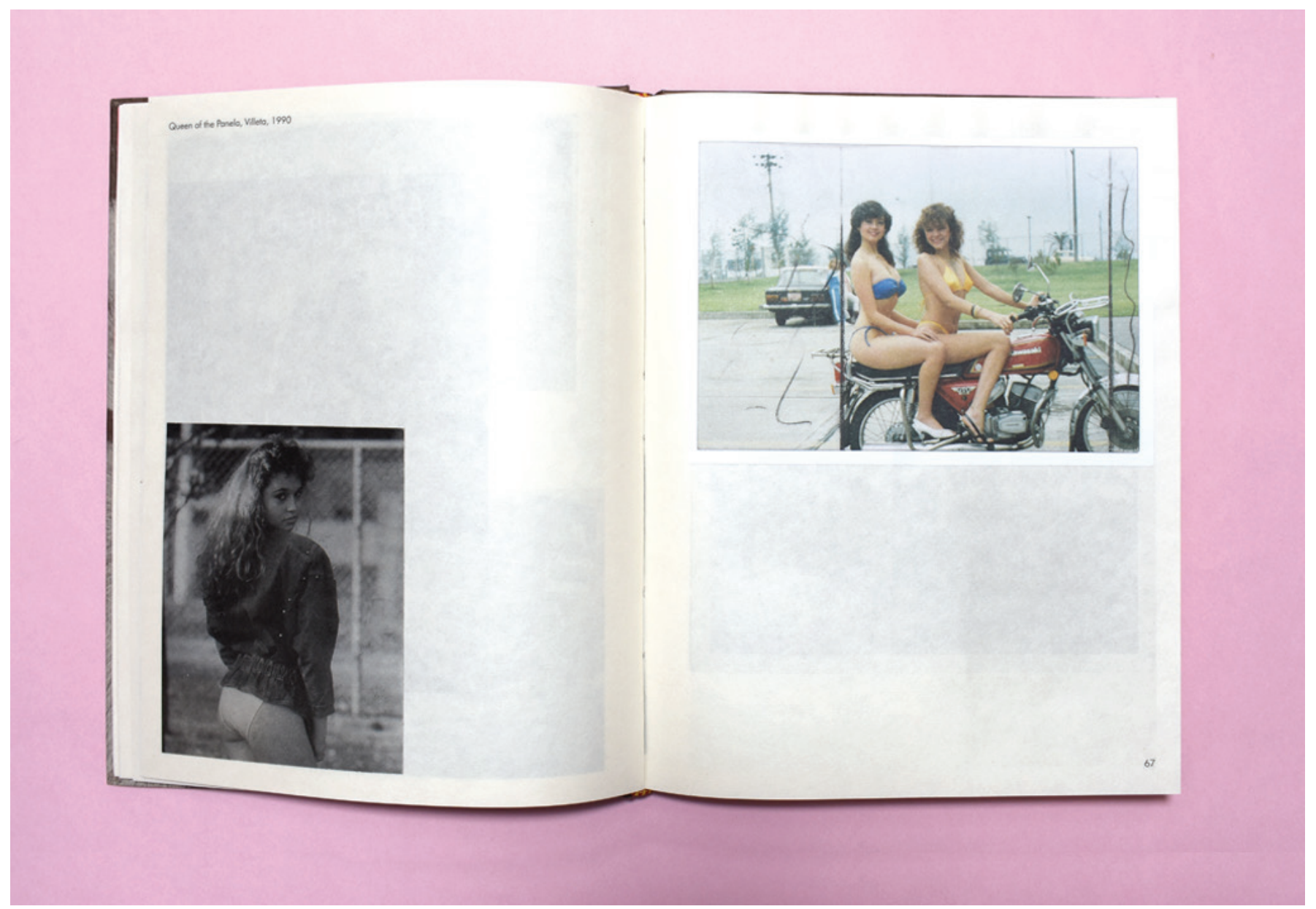

Imagen del libro: The cow and the orchid: generic colombian photography. Cortesía de Timothy Prus y La Silueta Ediciones (Valeria Giraldo, Andrés Fresneda y Juan Pablo Fajardo).

votada como las 10 peores de la historia. En Los aventureros la multitud asalta el palacio de gobierno de un "país banana" gobernado por un dictador. Para Prus las imágenes del rodaje son una extraña premonición de lo que ocurrirá 27 años después con la toma del palacio de justicia, y es francamente desconcertante, si abrimos el libro por primera vez en esas páginas, el no entender el suceso histórico que vemos, especialmente porque los cientos de extras que toman la plaza están recochando. Al menos en el rodaje, la revolución era una fiesta.

Un lugar especial en el libro lo ocupan las carátulas de álbumes de música tropical: los Univox, Emeterio y Felipe, los Hispanos, los hermanos López y Jorge Oñate, los Carrangueros, los Graduados y Gustavo Quintero, Jorge Oñate, Colacho Mendoza y su conjunto, los Legendarios, los Corraleros y la Sonora dinamita. Y estas carátulas sirven de bisagra para señalar hábitos y costumbres: los Carrangueros posando para el foto agüita, Emeterio y Felipe cazando el tigre de Zalamea, Jorge Oñate oficiando de cura en una boda... Parece que Prus nos invita a escuchar esta música para disfrutar a fondo esta fotografía genérica. Consecuentemente, aparece otro de los hábitos más enraizados para los colombianos, la rumba, y encontramos la gente tirando paso, la parejita amacizada cachete con cachete.

En esta fotografía colombiana, se ha excluido el lado siniestro de nuestra realidad. Prus, fundador del Archive of the modern conflict (Archivo del conflicto moderno) afirma que no le interesa insistir sobre el triste estereotipo de la Colombia violenta, y dice haber encontrado siempre un país muy diferente al que por décadas nos han vendido los medios de comunicación.

A cambio, inevitablemente y como es esperado, el libro tiene lugar para las orquídeas: las modelos, las chicas de calendario y las reinas de los tantos reinados que hay en el país, y Prus bautiza algunas de ellas: la Promenea gustatta, la Anguloa virginalis y... Paola Turbay, en palabras de Prus "la orquídea que ilumina el jardín de la familia". Y obviamente hay un lugar para las vacas. Prus tiene una colección de estas pastando 
en parques, metidas en los jardines de los barrios, en separadores y parqueaderos, como una fuerza del campo que se resiste a abandonar la ciudad. También aparece el ordeño y los niños mamando directamente de la teta del animal. La vaca evidentemente enlaza lo rural y lo urbano y la gigantesca transformació que definió la segunda kue definia abandonar la ciudad. ombianostoriadores que trabajan sobre este pan de la sociedad colombiana, el llamado 70/30, la inversión poblacional que definió la segunda mitad del Siglo XX. El libro concluye con una escueta imagen de dos orquídeas plásticas en materas sobre la tapa de un inodoro. La imagen es de Alberto Baraya, uno de los artistas que más ha querido indagar sobre el lugar de la flora como ornamento y más allá, de las fuerzas simbólicas que representan, en un país como el nuestro, exportador de los productos vegetales ilegales y legales de más alta calidad. Así, Prus pasa la orquídea a una generación más joven y nos deja este dulce y nostálgico homenaje a la cultura colombiana. 